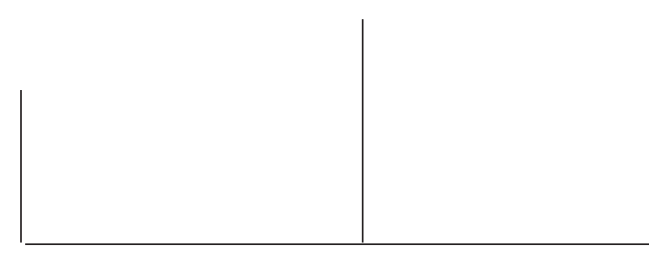

Rev. Latinoam. Psicopat. Fund., V, 2, 44-55

\title{
Desejo, remédio contra a angústia
}

\author{
Sandra Paes Barreto Edler
}

\begin{abstract}
A partir de recortes de um caso clínico e de um estudo preliminar sobre a angústia é nossa proposta neste trabalho discutir a idéia de Lacan (1962) acerca da constituição do desejo pelo ultrapassamento da angústia. Além disso, pretendemos analisar o desamparo na cultura como um dos fatores precipitantes de (novas?) manifestações de angústia que observamos na clínica psicanalítica.

Palavras-chave: Angústia, desejo, gozo, desamparo, processo analítico
\end{abstract}


Na clínica psicanalítica, tanto a depressão quanto a angústia, ao serem pensadas, colocam o analista frente à questão do desejo. O desejo, paralisado no caso das depressões, ou mantido ainda que a duras penas, no caso da angústia, interroga a posição do sujeito e deve ser analisado em sua possível relação ao gozo. Essas duas noções - desejo e gozo - foram situadas por Lacan (1958/1960) em oposição uma a outra.

Para que o sujeito possa desejar será necessário recusar o gozo, passando o desejo a vigorar como lei. Assim o desejo se situa como limite, como barreira interna ao gozo, de acordo com o conhecido aforisma lacaniano, "a castração quer dizer que é preciso que o gozo seja recusado para que possa ser alcançado na escala invertida da Lei do desejo" (1960, p. 807).

Inspirando-se no texto freudiano Inibição, sintoma e angústia (1926), Lacan observa, ao fim do Seminário 8 (1960), que, para que a angústia se constitua, é preciso que haja uma implicação do desejo. Em suas palavras, "o sinal de angústia tem uma ligação absolutamente necessária com o objeto do desejo. Sua função não se esgota na advertência de ter que fugir. Ao mesmo tempo em que realiza esta função, o sinal mantém a relação com o objeto de desejo" (1960, p. 352). Lacan nos apresenta, assim, a articulação entre a angústia e o desejo, ilustrando a idéia da constituição do desejo pelo ultrapassamento da angústia.

Esta observação foi o ponto de partida do nosso trabalho, que tem como proposta discutir, a partir de recortes de um caso clínico e de um estudo preliminar sobre a angústia, as inter-relações entre a angústia, o gozo e o desejo no processo analítico. Além disso, pretendemos analisar o desamparo na cultura como um dos fatores precipitadores de novas manifestações de angústia que observamos hoje na clínica psicanalítica. 


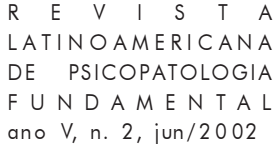

\section{Um caso clínico}

Como médica, Angélica procurou-me apresentando seu próprio diagnóstico, doença do pânico: crises de angústia durante as quais e sem razão aparente sentia um descompasso cardíaco, sudorese, aperto no peito e muito medo de morrer. $E$ aparecem do nada, comenta. Vivendo silenciosamente suas crises, entre as quais sentia-se permanentemente angustiada, concluiu o curso de medicina e em seguida casou-se, planejando para sua vida ser dona-de-casa e mãe, deixando de lado a profissão que, segundo ela, a expunha a todo o tipo de perigo e em particular o pior deles, o confronto com a morte.

Porque se meu medo fosse de leão ou de tigre seria simples, bastaria não viajar à África. Mas, sendo de morte, como posso exercer essa profissão? E faz a pergunta que dá início ao seu processo analítico, qual a saída para o meu problema? Pergunta a qual contraponho a idéia de qual seria a entrada. Angélica se reposiciona entre esses dois significantes, perguntando-se como entrar.

Ela interroga o desejo de ser médica paralisado pelo medo do confronto com a morte, tanto a sua quanto a do outro. Questiona também a escolha da especialidade guiada pelo medo, pelo pavor das doenças. É com alívio que chega à hipótese da pediatria: pelo menos já tive a maioria das doenças infantis. A sensação de alívio é ilusória e passageira. Em seu primeiro estágio verifica que, mesmo como pediatra, está diante do risco e dentro de um hospital, que associa à morte.

Um dia, Angélica acompanha a mãe numa cirurgia reparadora após a qual, subitamente, a mãe vem a falecer. Ao lado da mãe, no quarto, vira-se para pegar um objeto e depara-se com a mãe morta. Desespera-se. Agora mesmo é que não posso ser médica; vou tirar isso de uma vez da minha cabeça. Diante dessa afirmação feita num momento de intensa dor, eu lhe pergunto o que é isso que está lá e Angélica se confronta com o desejo que reluta em abandonar ou, como ela diz, do desejo que não quer me deixar mesmo sofrendo. Ser ou não ser médica. Como ser e como deixar de ser.

Angélica escondia, sempre que possível, sua condição de médica. Jamais usava roupa branca ou levava, consigo, maleta. Nada em sua aparência revelava a profissão. Esta postura, deliberada, visava protegê-la. Não queria ser chamada para socorrer quem quer que fosse e não olhava para os lados enquanto andava na rua: poderia, sem aviso prévio, estar diante da morte.

Depois da morte súbita da mãe, retoma ainda uma vez o atalho, na função de dona-de-casa, que inclui agora o pai. Quer ser a mama, significante que alude entre outros ao aspecto físico. Está muitos quilos acima de seu peso desde que começou a análise. Angélica é mais do que obediente, é submissa. Nesse momento de sua vida, ela se oferece ao pai como um objeto, para ser algo, recusando a condição de sujeito. 


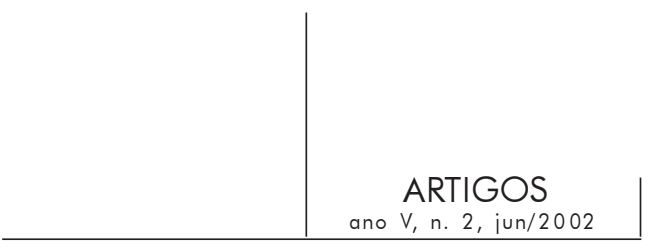

Assume, assim, uma posição masoquista submetendo-se ao que supostamente seria o desejo do pai, refúgio último à dor inerente à condição do sujeito.

Encontramos aqui o comentário de Lacan (1960/61) no sentido da fobia como forma radical de sustentação do desejo e da angústia como sinal do próprio desejo. Angélica construiu um sintoma fóbico a partir do qual passou a evitar o que supostamente lhe dava medo e criou uma vida de atalhos e recuos. Mas a angústia, como sabemos, não engana e não mente, mantinha-se ali, sinalizando o movimento latente do desejo. Angélica pensa e sonha. Ela que está gorda e se veste habitualmente de preto, em sonhos se vê magra e vestida de branco. Num cenário hospitalar, segura um bebê que acaba de nascer. Isso de novo, isso não me deixa. Nas associações posteriores ao sonho pensa em seu desejo de ser médica e discute a imagem magra que se confronta com seu atual momento. O que podem significar esses quilos a mais?, pergunto.

De início relutante em abordar o tema, Angélica depois associa a engorda à sua maneira de viver sem sair, sem satisfação sexual, estou muito distante disso. E próxima a quê?, pergunto. Ela se diz voltada ao pai, à tentativa de consolar sua viuvez. Ele não tem mais ninguém além de mim. Abre então um discurso sobre o pai, idealizado como homem e em sua função paterna. A crença no pai ideal e a luta para manter-se na posição de gozo a levam a ignorar a pergunta da analista: um pai assim tão poderoso não te deixaria fraca demais? Fraco demais está ele agora, triste e sozinho.

Mas, pouco tempo depois, o pai a chama para uma conversa. Fala de seu esforço e boa vontade em juntar os pedaços da família, todos abalados pela morte da mãe. No entanto deixa clara sua posição. Como viúvo quer viver sozinho o seu luto. Acha que Angélica deve deixá-lo e seguir a própria vida. Ouvindo o pai, Angélica se desespera, vivendo com dor, o luto pela fantasia tão cara de ser filha, mãe e mulher do pai.

O pai operou como pai simbólico impondo o limite necessário ao desejo que sabemos incestuoso. Ao lhe dizer minha filha, sou viúvo, sinalizou que, sendo filha, Angélica não poderia ser sua mulher. É um momento de retificação subjetiva em que Angélica, como sujeito, reconhece ser um nada, $a$, frente o desejo do Outro. Esse dito do pai produziu uma imediata mudança e Angélica, parada há muitos meses, começa a juntar suas coisas para voltar, com o marido, para o seu apartamento que ficou fechado. Antes de sair da casa do pai abre, pela última vez, o armário da mãe. Observa um álbum de capa dura que antes não havia chamado sua atenção, o álbum do bebê. Nele vê escrito seu nome.

Ao abri-lo observa, na primeira folha, detalhes sobre as condições de seu nascimento: local, hora, peso. Nasceu pequena e magra. Pouco depois, outro dado chama sua atenção: com um mês de vida mantinha-se com o mesmo peso. Por outro 


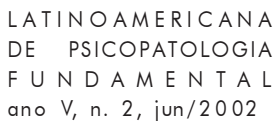

lado, ao completar um ano, era uma menina gorda. Angélica analisa os dados com o olhar de pediatra. A mãe, o desejo da mãe. Como foi recebida, alimentada, amada?

Revê agora sua identificação com a mãe que também era assim como eu, fóbica.

O pai, ao dispensá-la da função de grande mãe, de mama, operou um corte significante no gozo do sintoma. É o momento de pagar, com uma libra de carne, o preço do acesso ao desejo. Nutrição. Um significante novo chega às sessões. O que é nutrir, alimentar, amar uma criança. Vou cuidar de mim e das outras crianças. Outras crianças? E por que não? Ri, Angélica, diante do que disse.

O desejo, agora urgente, precipita uma série de atitudes. Angélica informa-se sobre nutrição e elabora sua própria dieta. $\mathrm{O}$ regime alimentar segue em paralelo aos estudos preparatórios ao concurso para especialista em pediatria. Do jogo de cartas marcadas que se organizava no sintoma fóbico, Angélica pode dar um salto: lançarse em busca de seu desejo sem qualquer garantia, sem saber se conseguiria, apenas voltando a andar. O risco que vislumbrava a cada instante na rua, no hospital e nos olhos do outro, de certa maneira mantém-se no movimento do desejo, um jogo sem regras predeterminadas cujo único efeito é, talvez, o efeito parcial de sentido e o passo vacilante em lugar da anterior rigidez.

Poder tomar a angústia como uma pergunta sobre o desejo do sujeito é possivelmente a questão maior de uma análise. Cumprindo uma função de aviso, a angústia mantém a relação do sujeito com o objeto de seu desejo propondo uma questão aberta sobre sua verdade, isto é, o que é o sujeito como sujeito desejante, o que causa o desejo nele.

\section{Entre o gozo e o desejo, a angústia}

A observação de Lacan, que mencionamos no sentido de implicar a angústia ao desejo, permite pensar uma outra dimensão à idéia freudiana (1926) de angústia sinal como angústia sinal de desejo, angústia como contraface do desejo, o sinal que precede sua emergência.

É no texto de 1926 que Freud revê a primeira teoria da angústia segundo a qual este afeto primordial é problematizado em seu aspecto econômico, decorrente de um transbordamento da libido (no caso, da neurose de angústia) ou ainda resultante de um desvio da libido que não encontrou escoamento adequado. Nesse segundo caso estariam as psiconeuroses. A libido, desligada pelo recalque de suas representações, irromperia sob a forma de angústia.

Neste momento de seu percurso Freud (1916), tendo estabelecido a etiologia sexual das neuroses, propõe a tese de que o recalque seria a causa, ou melhor, a razão 


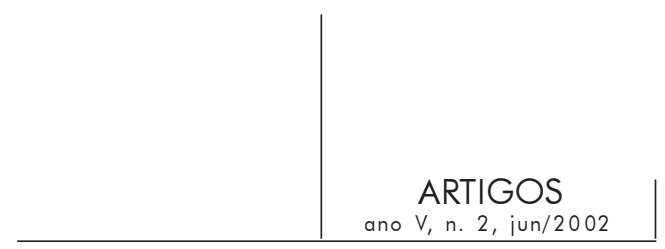

do acúmulo de excitação não passível de ser descarregada. Seria o recalque que presidiria a irrupção da angústia.

Em "Inibição, sintoma e angústia" (1926), esta formulação é revista e Freud, fazendo uma crítica em relação à sua primeira teoria, admite que é a angústia que causa o recalque, não sendo produtivo buscar, neste afeto, sentidos recalcados. $\mathrm{O}$ enunciado de 1926 que registra esta alteração ficou conhecido como a segunda teoria da angústia.

Ainda neste texto Freud associa a angústia à angústia de castração, que põe em movimento o recalque e diferencia a angústia do luto e da fobia, problematizando a questão da não existência de um objeto para a angústia, questão que Lacan irá reformular em seu seminário sobre o tema (1962).

Lacan vai se opor à tese freudiana da angústia referida ao Édipo e à castração por situar estas operações no registro do simbólico. Em sua ótica, a angústia irrompe no encontro do sujeito com o Real, encontro este que o paralisa em sua condição de sujeito desejante. No caso de Angélica, depois do casamento, ela deu legitimidade ao medo, dando a ele um revestimento de opção existencial. Ser dona-de-casa e mãe significava, principalmente, poder se refugiar em casa, livrando-se do mal-estar das ruas, dos clientes e do hospital. Em suas palavras, de ter que ver a morte todos os dias. Quando assumiu o papel de mama, Angélica refugiou-se na cozinha da casa do pai, querendo satisfazê-lo em seus (supostos) caprichos alimentares. Paralisada em seu desejo, vivendo intensamente a condição de gozo, Angélica fixou-se em casa, engordando quase $40 \mathrm{~kg}$.

A angústia entre o gozo e o desejo é uma formulação do Seminário 10 (Lacan, 1962), que situa ainda a existência de um objeto da angústia que é o mesmo objeto do desejo, o objeto $a$. A angústia estaria ancorada no desejo do Outro: não podemos saber que objeto $a$ somos em relação ao desejo do Outro. Só imaginariamente podemos supor nossa posição no desejo parental e aí construímos nossa fantasia.

Em resposta à tese de Freud, no sentido de que a angústia seria um temor sem objeto, Lacan, nesse seminário, afirma, ao contrário, que "ela não é sem objeto" (1962, p. 141), embora este objeto, muito especial, não seja acessível pela mesma via que os outros. A angústia, Lacan nos diz, leva-nos a pensar na incidência da falta. A angústia emerge quando a falta falta e o objeto causa do desejo, que deveria ficar oculto, torna-se visível. "A angústia, de todos os sinais, é aquele que não engana" (Ibid., p.198). É do Real, portanto, que a angústia é sinal.

Lacan vai demonstrar como e em que condições este sinal vai se manifestar, por meio da idéia de que a angústia guarda uma função mediana entre o gozo e o desejo. "Falei da angústia enquanto termo intermediário entre o gozo e o desejo, na medida em que é, ultrapassada a angústia, que o desejo se constitui" (Ibid., p. 215). Quando se estreita a distância entre gozo e desejo a angústia surge como sinal, toque de alerta, sinalizando o aparecimento do objeto $a$ no lugar onde não se esperava encontrar nada. 


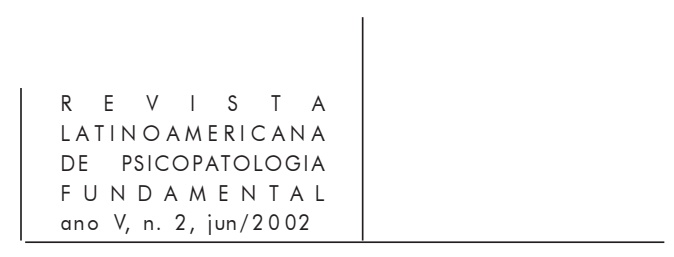

O objeto $a$ comparece como construção do sujeito frente ao desejo do Outro. Tratase, neste momento, da irrupção de algo estranho (Unheimliche), um instante de desorganização, descompasso e estranheza que deixa o sujeito suspenso, paralisado. Lacan se vale de "O estranho" (Freud, 1919) por considerar este texto "a dobradiça indispensável para abordar a questão da angústia" (1962, p. 49).

Harari (1997), comentarista de Lacan, observa que o objeto em questão é justamente o que se designou como a-Coisa, ou seja, o desejo do Outro enquanto exigência de que o sujeito apague seus limites, desfazendo-se. Esta seria a expressão máxima do gozo e que, de uma forma ou de outra, vai atrelar-se ao círculo repetitivo da compulsão à repetição, vindo à luz no sintoma.

De acordo com este autor, no pano de fundo do Seminário 10 está a idéia de que a angústia surge como sinal quando se estreitam as distâncias entre o gozo e o desejo: a angústia sinaliza a posição do sujeito frente ao desejo do Outro, adverte, impõe-se como fenômeno de borda. Aplacá-la de imediato impediria, assim, que ela exercesse sua função de alerta.

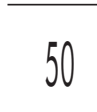

\section{Angústia e fobia}

Precocemente em seu percurso Freud descreveu fenomenologicamente a crise de angústia. Em 1895, ao introduzir a neurose de angústia destacando-a da neurastenia, faz a descrição de um quadro clínico que tem início com uma crise na qual o afeto de angústia pode ser acompanhado de um distúrbio de uma ou mais funções corporais inclusive os distúrbios da atividade cardíaca como palpitações, arritmia transitória ou taquicardia de duração mais longa.

Depois da primeira crise, instala-se um quadro de expectativa angustiosa. Freud (Ibid.) observou que este quadro de permanente tensão antes, durante e depois das crises irá, mais tarde, ligar-se a representações que irão se organizar de algum modo, como, por exemplo, no caso das fobias.

À descrição do quadro clínico segue-se uma proposta teórica na qual Freud coloca a idéia de que a excitação acumulada sem possibilidade de descarga compatível com sua intensidade possa gerar essas manifestações. "Essas indicações levam-nos a esperar que o mecanismo da neurose de angústia deva ser procurado em uma deflexão da excitação sexual somática da esfera psíquica, com conseqüente emprego anormal dessa excitação" (Ibid., p. 126). Assim, nesta fase inicial de seu trabalho Freud já esboça a idéia da angústia como um afeto, a fonte de excitação como interna - diferente, portanto, de uma fonte externa que teria relação mais imediata com o medo e esta forma peculiar de manifestação da angústia a partir de uma primeira crise. 


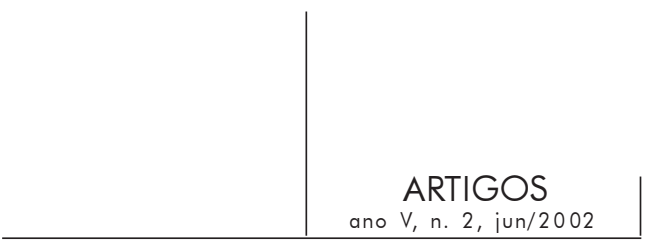

Dessa abordagem registramos a descrição clínica a nosso ver bastante semelhante ao que hoje é conhecido como síndrome do pânico: crises de aparecimento súbito, que se repetem, com intervalos nos quais o sujeito mantém-se ansioso. Não estamos aqui nos referindo à crise de angústia única, de grande mobilização psíquica, mas a crises que se repetem sem uma razão aparente, crises que assustam e que levam o sujeito a se perguntar o porquê delas ou, como nos diz Freud, "sem nenhuma idéia associada ou então acompanhada da interpretação que estiver mais a mão, tais como idéias de extinção da vida... ou ainda de uma ameaça de loucura..." (Ibid., p. 111). Ou seja, a angústia em estado livre.

Vemos nestas crises o corpo do sujeito reduzido a sua condição de organismo: funções vitais em desordem, ameaçando-o de morte. Sinto medo, pânico!, diz a paciente do caso que estamos estudando. Pânico de quê? De morrer. Na hora penso: estou infartando! E o intervalo entre as crises transforma o tempo num tempo de desassossego, de apreensão: não sei o que provoca isso que tenho. Deixei de viver desligada, distraída. Passei como que a... vigiar a vida. Vivo com medo de morrer. O corpo em desordem se torna um corpo estranho e assustador, ameaçado de colapso.

A crise de pânico, ao desestruturar os parâmetros de tempo e espaço ampliando distâncias e tornando perigosos e difíceis pequenos passos, remete o sujeito que passa por esta experiência ao estado mais absoluto de desamparo. Sem saber o porquê das crises e, portanto, o que evitar, o sujeito se transforma num fugitivo sem rumo.

A fobia se organiza num segundo momento, quando uma representação é fixada, eleita a soldadura (Verlötung) e é definido então o objeto fóbico: algo a ser evitado. Como nos alerta Freud, desde seu artigo de 1895, situações que envolvem espaços abertos apresentariam condições favoráveis ao desencadeamento de tais crises que, não raro, assemelham-se às agorafobias. A primeira crise de angústia ocorre com frequiência fora da casa do sujeito: na rua, no shopping, no interior de uma igreja. A casa se torna, assim, o refúgio, o eixo de segurança do sujeito.

Diante do espaço aberto que atemoriza, a dinâmica fóbica precipita um mapeamento. O espaço e o tempo são reorganizados a partir dessa primeira crise de angústia. No caso de Angélica, na fase inicial de análise, ela preferia sessões na parte da manhã ou no início da tarde. Evitava sempre que possível sair de casa ao anoitecer. A questão da distância entre sua casa e o meu consultório, não muito grande, foi resolvida, imaginariamente, através da criação de ilhas de segurança, as farmácias. Angélica ia e voltava a pé visualizando, sempre que possível, uma farmácia, local que elegeu como seguro. Onde posso respirar, dizia. 


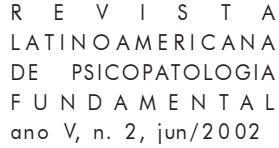

\section{Pânico, um novo nome para o desamparo}

Manifestações de angústia sempre existiram: a angústia sinal, aquela que é da ordem do signo e que representa um perigo para o eu, e a angústia automática, desencadeada diante de uma situação traumática que, segundo Pereira (1999), é da ordem do terror e aponta para o esmagamento do aparelho psíquico, são, ambas, modalidades de aparecimento da angústia que fazem parte de nossa clínica cotidiana. $\mathrm{O}$ suposto aumento dessas manifestações ou o surgimento de uma nova modalidade chamada de síndrome do pânico nos levam a uma série de interrogações. Estaria o sujeito, hoje, mais angustiado? Estaria o desamparo potencializado, precipitando o surgimento dessas peculiares manifestações de angústia?

Freud (1927, 1930), como sabemos, situa o desamparo como constitutivo, definindo o homem como uma criatura frágil e imatura, incapaz de manter-se e dependente de um outro para sobreviver. Ele se baseia no modelo do recém-nascido cujo aparelho motor, precário, não apresenta condições de autonomia para satisfazer suas necessidades básicas. Paralelamente, o mesmo acontece com o aparelho psíquico, incapaz de dominar a carga de excitação oriunda de fonte somática. O desamparo psíquico é, assim, correlato ao desamparo motor.

A frágil condição do recém-nascido, no entanto, não é totalmente sanada com o desenvolvimento. Desta maneira, não podemos pensar o desamparo como um estado afetivo inerente ao estágio inicial da vida. Em "O futuro de uma ilusão", Freud (1927) deixa claro a idéia de que não há remédio para o desamparo, situando como permanente a condição de precariedade do homem. Nessa medida, ele estaria sempre nostálgico de um pai ou ansiando pelo suporte dos deuses. Nas palavras de Pereira (1999), "confrontado, sem estar preparado a esta condição de desamparo, o aparelho psíquico constrói figuras divinas protetoras que, em última instância, lhe faltam dolorosamente" (p. 225).

Em seu último grande texto, "Moisés e o monoteísmo" (1939), Freud retorna ao tema do desamparo, articulando-o à função paterna. A questão do declínio do pai, desenvolvida mais tarde por Lacan, não passou despercebida a Freud, que, neste texto, esboça a idéia do declínio por meio da figura de Moisés, o grande homem, o legislador, o pai que guia o povo em direção à terra prometida. Na opinião de Pereira, "Trata-se, para Freud, de executar a destruição da divindade Moisés para que o homem Moisés, menos idealizado e, talvez por isso mesmo, menos perseguidor, possa advir" (p. 218).

Lacan, desde Os complexos familiares (1938), propõe a idéia do declínio da figura do pai na cultura contemporânea. Outros autores (Delumeau, Roche, 1990) vêm corroborando este pensamento, ilustrando, do ponto de vista histórico, o declínio do pai em sua dimensão sociojurídica. O lugar e a função do pai na cultura sofreram 


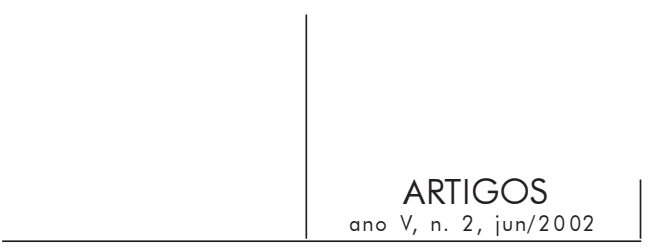

enormes modificações através dos tempos e, sobretudo, de maneira acelerada, na segunda metade do século XX.

Novas formas de casamento, a multiplicação de filhos de diferentes relacionamentos, produções independentes, entre outros fatores, estariam favorecendo tais modificações havendo quem sugira (Miller, 1979) que parte da função norteadora do pai na cultura está sendo substituída por comitês de ética: grupos de iguais que, em determinado momento, circunscrevem o que é legítimo, aceitável e conveniente frente esta ou aquela situação. Mas os comitês de ética, mutantes, estão longe de dar suporte ao sujeito da atualidade. O lugar vazio deixado pela ausência do pai aponta para os riscos de uma existência sem garantias. Como pensar, hoje, em nossa cultura, a condição humana do desamparo?

Em sua discussão sobre o mal-estar na pós-modernidade, Bauman (1998) observa a questão do movimento e da fugaz transitoriedade que, em sua opinião, caracterizam nosso tempo. Assim, se analisarmos por um lado o sujeito, precário em seu instrumental, e, por outro, as peculiaridades de nossa cultura, na qual a autoridade está desmoronando e as incertezas substituindo cada vez mais as antigas certezas, num pano de fundo em constante modificação, podemos concluir que o sujeito estaria, hoje, duplamente desamparado, sem pai, sem mestre e sem deus. Os antigos parâmetros sociais que configuravam os papéis de pais e mestres, e mesmo do Estado que em algum nível daria suporte ao cidadão, sofreram, hoje, uma drástica e rápida modificação. Vivemos um jogo no qual as regras mudam incessantemente, "o nome do jogo é mobilidade", comenta ainda o autor (p. 114).

Diante deste mutável contexto no qual quase tudo se altera rapidamente, o desejo traz o sujeito para sua trilha, circunscreve seu caminho. São muitos os obstáculos que fazem o sujeito ceder de seu desejo, o serviço de bens, como designou Lacan (1960), o suposto bem do outro e, acrescentaríamos, o medo. Nesse momento é que a angústia, dada sua singular proximidade com o desejo, pode dar o seu sinal, apontando ao sujeito, para além dos riscos e da desenfreada busca de garantias, sua condição de incurável solidão e as múltiplas possibilidades de seu desejo.

No caso que estamos estudando, só no momento em que ficou sem a mãe e quando foi dispensada pelo pai da suposta tarefa de atendê-lo sentindo-se totalmente só, despossuída da fantasia tão cara de suplência da mãe, é que Angélica, dizendose há anos desejosa de seguir sua profissão, finalmente faz das palavras, ação. Momento de concluir em ato o desejo de dispensar as amarras do gozo e criar seu próprio movimento desejante. Momento em que o desejo tomou corpo e tornou-se um motor, e o medo, não totalmente superado, pôde ser ultrapassado naquela peculiar travessia. 


\section{Referências}

Bauman, Z. O mal-estar na pós-modernidade. Rio de Janeiro: Jorge Zahar, 1998.

FREUD, S. (1895). Sobre os critérios para destacar da neurastenia uma síndrome particular intitulada neurose da angústia. In: Edição Standard Brasileira das Obras Psicológicas Completas de Sigmund Freud. Rio de Janeiro: Imago, 1976. v. III. (1916). Conferências introdutórias sobre psicanálise, conferência XXV. In: ESB., op. cit. v. XVI.

(1919). O estranho. In: E.S.B., op. cit. v. XVII.

(1926). Inibição, sintoma e angústia. In: E.S.B., op. cit. v. XX.

(1927). O futuro de uma ilusão. In: E.S.B., op. cit. v. XXI.

(1930). O mal-estar na civilização. In: E.S.B., op. cit. v. XXI.

(1939). Moisés e o monoteísmo. In: E.S.B., op. cit. v. XXIII.

LACAN, J. Subversão do sujeito e dialética do desejo no inconsciente freudiano. In: Escritos. Rio de Janeiro: Jorge Zahar, 1998.

(1938). Os complexos familiares na formação do indivíduo. Rio de Janeiro: Jorge Zahar, 1987.

(1960-1961). O seminário. Livro 8. A transferência. Rio de Janeiro: Jorge Zahar, 1992.

(1962-1963). O seminário - A angústia. Recife: Centro de Estudos Freudianos do Recife (publicação para circulação interna), 1997.

Harari, R. Seminário "A angústia" de Lacan: uma introdução. Porto Alegre: Artes e Ofícios, 1997.

Miller, J.-A. L'Autre qui n'existe pas et ses comités d'éthique - introducion. Revue de psychanalyse la cause freudienne, n. 35, p. 7-14, 1997.

Pereira, M.E. Costa. Pânico e desamparo. São Paulo: Escuta, 1999.

\section{Resumos}

A partir de recortes de un caso clínico y de un estudio preliminar sobre la angustia es nuestra propuesta, en el presente trabajo, discutir la idea de Lacan (1962) a respecto de la constitución del deseo por el traspasamiento de la angustia. También pretendemos analizar el desamparo en la cultura como uno de los factores precipitantes de (nuevas?) manifestaciones de angustia que observamos en la clínica psicoanalítica.

Palabras clave: Angustia, deseo, gozo, desamparo, proceso psicoanalítico

A partir de fragments d'un cas clinique et d'une étude préliminaire sur l'angoisse, nous nous proposons de discuter ici l'idée de Lacan (1962) sur la constitution du désir 


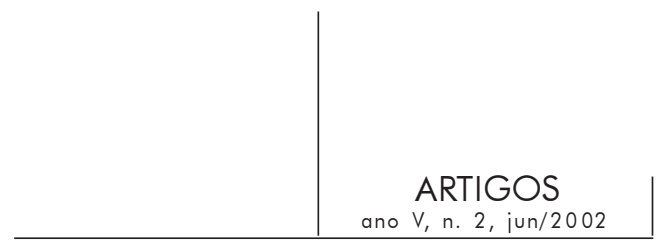

par le dépassement de l'angoisse. Nous avons également pour but d'analyser l'état de détresse dans la culture, comme l'un des facteurs déclenchant les (nouvelles?) manifestations d'angoisse que nous signalons dans la clinique psychanalytique.

Mots clés: Angoisse, desir, jouissance, detresse, procès analitique

Based on vignettes from a clinical case and from a preliminary study on anxiety, our purpose here is to discuss Lacan's idea (1962) of the constitution of desire by overcoming anxiety. We also intend to analyze the failings of society as one of the factors that trigger off further occurrences of anxiety as observed in the psychoanalytic clinic.

Key words: Anxiety, desire, "jouissance”, analytic process 